\title{
CLORETO DE POTÁSSIO E FOSFATO DE SÓDIO NA MULTIPLICAÇÃo IN VITRO DE AMOREIRA-PRETA CV. TUPY
}

\author{
Effect of $\mathrm{KCl}$ and $\mathrm{NaH}_{2} \mathrm{PO}_{4} \cdot \mathrm{H}_{2} \mathrm{O}$ on in vitro multiplication of blackberry cv. Tupy
}

\author{
Fabíola Villa ${ }^{1}$, Moacir Pasqual², Leila Aparecida Salles Pio $^{1}$, Grazielle Sales Teodoro $^{3}$, Luzia Yuriko Miyata ${ }^{4}$
}

\begin{abstract}
RESUMO
A micropropagação da amoreira-preta pode gerar plantas livres de vírus e em curto espaço de tempo. Com o objetivo de aprimorar técnicas de micropropagação de amoreira-preta cv. Tupy (Rubus spp.), segmentos nodais com cerca $2 \mathrm{~cm}$ e 2 gemas axilares, oriundos de plantas pré estabelecidas in vitro, foram excisados e inoculados em meio de cultura MS, suplementado com diferentes concentrações de fosfato de sódio $\left(0,125,250,500\right.$ e $\left.1000 \mathrm{mg} \mathrm{L}^{-1}\right)$ e de cloreto de potássio $\left(0,125,250,500\right.$ e $\left.1000 \mathrm{mg} \mathrm{L}^{-1}\right)$. $\mathrm{O}$ pH foi ajustado para 5,8 antes da adição de $6 \mathrm{~g} \mathrm{~L}^{-1}$ de ágar e da autoclavagem a $121^{\circ} \mathrm{C}$ e $1 \mathrm{~atm}$ por 20 minutos. Após a inoculação, os explantes foram transferidos para sala de crescimento a $25 \pm 1^{\circ} \mathrm{C}$, irradiância de $35 \mathrm{mmol} \mathrm{m}^{-2} \mathrm{~s}^{-1}$ e fotoperíodo de 16 horas, onde permaneceram por 60 dias. O delineamento experimental utilizado foi inteiramente casualisado, utilizando-se de quatro repetições constituídas de três tubos de ensaio contendo um explante cada. O número de brotos e o comprimento da parte aérea das plantas foi menor em função de maiores concentrações de cloreto de potássio. Melhores resultados foram obtidos na ausência de $\mathrm{KCl}$ e na presença de fosfato de sódio, principalmente para comprimento e matéria fresca da parte aérea.
\end{abstract}

Termos para indexação: Rubus spp., micropropagação, macronutrientes.

\begin{abstract}
The micropropagation of blackberry can generate virus-free plants in short time. In order to improve micropropagation techniques of blackberry cv. Tupy (Rubus spp.), nodal segments with $2 \mathrm{~cm}$ length and 2 axillary buds originating from plants in vitro were excised and inoculated in MS culture medium, supplemented with different concentrations of sodium phosphate $(0,125,250$, 500 and $\left.1000 \mathrm{mg} \mathrm{L}^{-1}\right)$ and potassium chloride $\left(0,125,250,500\right.$ and $\left.1000 \mathrm{mg} \mathrm{L}^{-1}\right)$. The $\mathrm{pH}$ was adjusted to 5.8 before the addition of $6 \mathrm{~g} \mathrm{~L}^{-1}$ agar and sterilization at $121^{\circ} \mathrm{C}$ and $1 \mathrm{~atm}$ for 20 minutes. After the inoculation, the explants were transferred to growth room at $25 \pm 1^{\circ} \mathrm{C}, 35 \mathrm{mmol} \mathrm{m} \mathrm{m}^{-2} \mathrm{~s}^{-1}$ irradiance and photoperiod of 16 hours, where they stayed for 60 days. The experiment was arranged in a completely randomized design, using four repetitions with 12 plants each. Number of sprouts and length of the aerial part of plants were smaller, due to larger concentrations of potassium chloride. Better results were obtained in the absence of $\mathrm{KCl}$, and in the presence of sodium phosphate, mainly for length and fresh weight of the aerial part.
\end{abstract}

Index terms: Rubus spp., micropropagation, macronutrients.

(Recebido em 10 de agosto de 2006 e aprovado em 12 de abril de 2007)

\section{INTRODUÇÃO}

Apesar de ser uma fonte de renda alternativa para pequenos produtores, no Brasil o cultivo da amoreira-preta não está tão difundido como na Europa, sendo a qualidade das mudas um fator limitante (ANTUNES \& RASEIRA, 2004). Desde os anos 80, existe a possibilidade de micropropagação de muitas culturas, inclusive framboesa e amora preta (DONNELLY \& DAUBENY, 1986; FINNE, 1986). Entretanto, a elevada variabilidade de comportamento das espécies in vitro requer a adequação de condições de cultivo para cada espécie em específico, pois nem todas as espécies de Rubus demonstram grande coeficiente de propagação in vitro (JENNINGS \& McNICOL, 1991; LEONTIEV-ORLOV, 1989).

O meio de cultura deve suprir tecidos e órgãos cultivados in vitro com nutrientes necessários ao crescimento. Os macronutrientes são fornecidos ao meio de cultura na forma de sais. Cálcio, magnésio e potássio são absorvidos pelas células vegetais como cátions $\left(\mathrm{Ca}^{+2}\right.$, $\mathrm{Mg}^{+2}$ e $\mathrm{K}^{+}$); nitrogênio na forma de amônio $\left(\mathrm{NH}^{+}\right)$ou nitrato $\left(\mathrm{NO}_{3}^{-}\right)$; fósforo como íons fosfato $\left(\mathrm{HPO}_{4}\right)$ e $\left(\mathrm{H}_{2} \mathrm{PO}_{4}\right)^{-}$. Os sais usados para fornecer macronutrientes também podem

\footnotetext{
${ }^{1}$ Engenheiras Agrônomas, Doutorandas em Fitotecnia - Departamento de Agricultura/DAG - Universidade Federal de Lavras/UFLA - Cx. P. 3037 37200-000 - Lavras, MG - fvilla2003@libero.it; leilapio@ufla.br

${ }^{2}$ Engenheiro Agrônomo, Doutor, Professor Adjunto - Departamento de Agricultura/DAG - Universidade Federal de Lavras/UFLA - Cx. P. 3037 - $37200-000$ Lavras, MG - mpasqual@ufla.br

${ }^{3}$ Graduanda em Ciências Biológicas - Departamento de Agricultura/DAG - Universidade Federal de Lavras/UFLA - Cx. P. 3037 - $37200-000$ - Lavras, MG gsales.bio@gmail.com

${ }^{4}$ Graduanda em Agronomia - Departamento de Agricultura/DAG - Universidade Federal de Lavras/UFLA - Cx. P. 3037 - $37200-000$ - Lavras, MG luziaym@yahoo.com.br
} 
fornecer íons dos elementos sódio $\left(\mathrm{Na}^{+}\right)$e cloro $\left(\mathrm{Cl}^{-}\right)$, sendo que as células vegetais toleram bem altas concentrações dos mesmos (PASQUAL, 2001). O potássio entra como íon acompanhante do nitrato, fosfato ou, em alguns casos, do cloreto. $\mathrm{O}$ íon exerce suas funções metabólicas e bioquímicas na planta, e nas células in vitro, como íon livre, sem incorporação em compostos orgânicos, tornando seu metabolismo muito simples (CALDAS et al., 1998).

$\mathrm{O}$ fosfato de sódio $\left(\mathrm{NaH}_{2} \mathrm{PO}_{4} \cdot \mathrm{H}_{2} \mathrm{O}\right)$ é um componente do meio White (1963) e B5 (GAMBORG et al., 1968). O cloreto de potássio $(\mathrm{KCl})$ é encontrado somente no meio White (1963). O meio MS possui baixas concentrações de sódio e cloro, porém, estudos com a micropropagação de orquídeas demostraram a necessidade de se adicionar ao meio concentrações maiores desses sais. Em estudos com orquídeas Phalaenopsis nebula, verificou-se regeneração de plantas através de cultura de calos, em meio MS, com a adição de $170 \mathrm{mg} \mathrm{L}^{-1}$ de fosfato de sódio (CHEN et al., 2000).

Neste trabalho, objetivou-se determinar a melhor concentração de cloreto de potássio e fosfato de sódio na multiplicação in vitro de plantas de amoreira-preta.

\section{MATERIAL E MÉTODOS}

Segmentos nodais de amoreira-preta cultivar Tupy, com cerca de $2 \mathrm{~cm}$ de comprimento e 2 gemas axilares, foram excisados de plantas pré estabelecidas in vitro, em meio de cultura MS (MURASHIGE \& SKOOG, 1962), sem reguladores de crescimento. Estes foram inoculados em tubos de ensaio contendo $15 \mathrm{~mL}$ do meio de cultura. Os tratamentos consistiram de diferentes concentrações de fosfato de sódio $\left(0 ; 250 ; 500 ; 750\right.$ e $\left.1000 \mathrm{mg} \mathrm{L}^{-1}\right)$ e cloreto de potássio $\left(0 ; 250 ; 500 ; 750\right.$ e $\left.1000 \mathrm{mg} \mathrm{L}^{-1}\right)$. O meio foi acrescido de $30 \mathrm{~g} \mathrm{~L}^{-1}$ de sacarose e solidificado com $6 \mathrm{~g} \mathrm{~L}^{-1}$ de ágar $\left(\right.$ Merck $\left.^{\circledR}\right)$ e o pH ajustado para 5,8, antes da autoclavagem a $121^{\circ} \mathrm{C}$ e 1 atm por 20 minutos. Posteriormente à inoculação, os explantes foram transferidos para sala de crescimento a $25 \pm 2^{\circ} \mathrm{C}$, irradiância de $35 \mathrm{mmol} \mathrm{m} \mathrm{m}^{-2} \mathrm{~s}^{-1}$ fornecida por tubos fluorescentes de 20W (Osram ${ }^{\circledR}$ ), luz do dia especial e fotoperíodo de 16 horas diárias, permanecendo nestas condições por 60 dias. $\mathrm{O}$ delineamento experimental utilizado foi inteiramente casualisado, utilizando-se de quatro repetições com 12 plantas cada.

Foram avaliados os parâmetros número de folhas, número de brotos, comprimento e matéria fresca da parte aérea e matéria fresca de calos. Os dados foram analisados através do software Sisvar (FERREIRA, 2000), sendo utilizado regressão polinomial para as concentrações dos sais.

\section{RESULTADOS E DISCUSSÃO}

Através da análise de variância para a variável número de folhas da amoreira-preta 'Tupy', verifica-se que, o maior número de folhas $(7,1)$ foi obtido com $1000 \mathrm{mg} \mathrm{L}^{-1}$ de $\mathrm{KCl}$ e $125 \mathrm{mg} \mathrm{L}^{-1}$ de $\mathrm{NaH}_{2} \mathrm{PO}_{4} \cdot \mathrm{H}_{2} \mathrm{O}$ (Figura 1).

Mesmo na ausência do cloreto de potássio, houve formação de folhas nas plantas desta cultivar, porém, com o aumento das dosagens deste sal, observou-se queda no número de folhas, exceto para a concentração de $125 \mathrm{mg} \mathrm{L}^{-1}$ de fosfato de sódio; talvez devido ao fato de, altas dosagens serem tóxicas aos explantes estudados.

Maior número de folhas de crisântemo foi obtido com a adição de $1000 \mathrm{mg} \mathrm{L}^{-1}$ de nitrato de cálcio ao meio MS, na ausência de KCl (JUNQUEIRA et al., 2003).

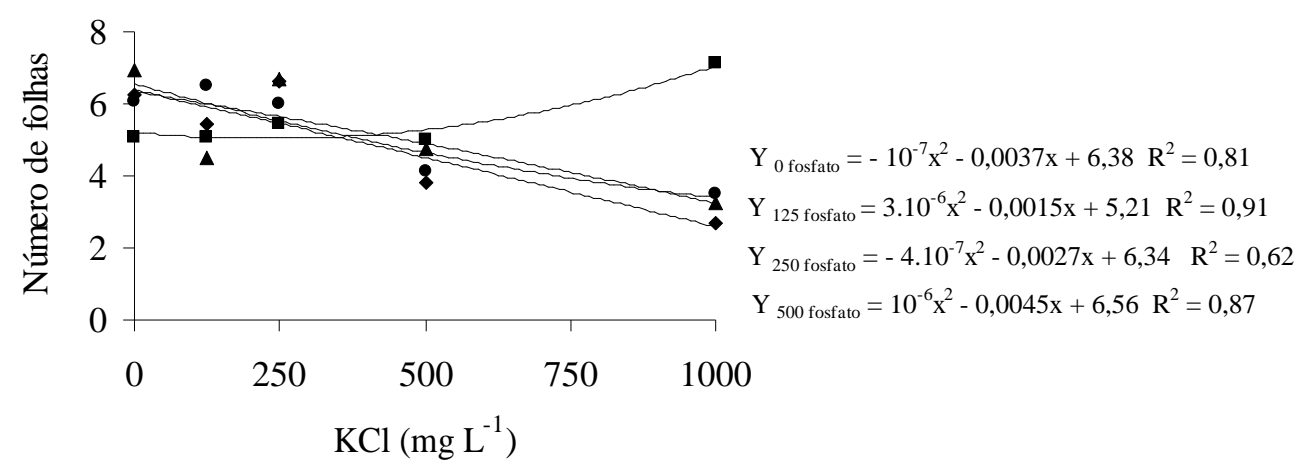

\begin{tabular}{|ll|}
\hline - 0 fosfato de sódio & - 125 fosfato de sódio \\
- 250 fosfato de sódio & - 500 fosfato de sódio \\
\hline
\end{tabular}

Figura 1 - Número de folhas de plantas de amoreira-preta cv. Tupy em diferentes concentrações de cloreto de potássio $(\mathrm{KCl})$ e fosfato de sódio $\left(\mathrm{NaH}_{2} \mathrm{PO}_{4} \cdot \mathrm{H}_{2} \mathrm{O}\right)$. UFLA, Lavras, MG. 
Amarelecimento das folhas e enfraquecimento das hastes também foram observados nos tratamentos que continham o cloreto de potássio, corroborando com Pasqual (2001), ao afirmar que concentrações muito elevadas de cloro em algumas espécies lenhosas podem favorecer o aparecimento desses sintomas.

$\mathrm{Na}$ dosagens de 750 e $1000 \mathrm{mg} \mathrm{L}^{-1}$ de $\mathrm{KCl}$ foi verificada hiperhidricidade nas folhas de 'Tupy', onde o excesso de cloro é uma de suas causas (PASQUAL, 2001).

Pode-se observar multiplicação de brotos na ausência do $\mathrm{KCl}$, porém, o número de brotos das plantas foi menor em função de maiores concentrações de cloreto de potássio (Figura 2).

Nota-se que os melhores resultados foram obtidos na ausência do cloreto de potássio e na adição de fosfato de sódio ao meio MS, principalmente para comprimento e matéria fresca da parte aérea (Figuras 3 e 5).

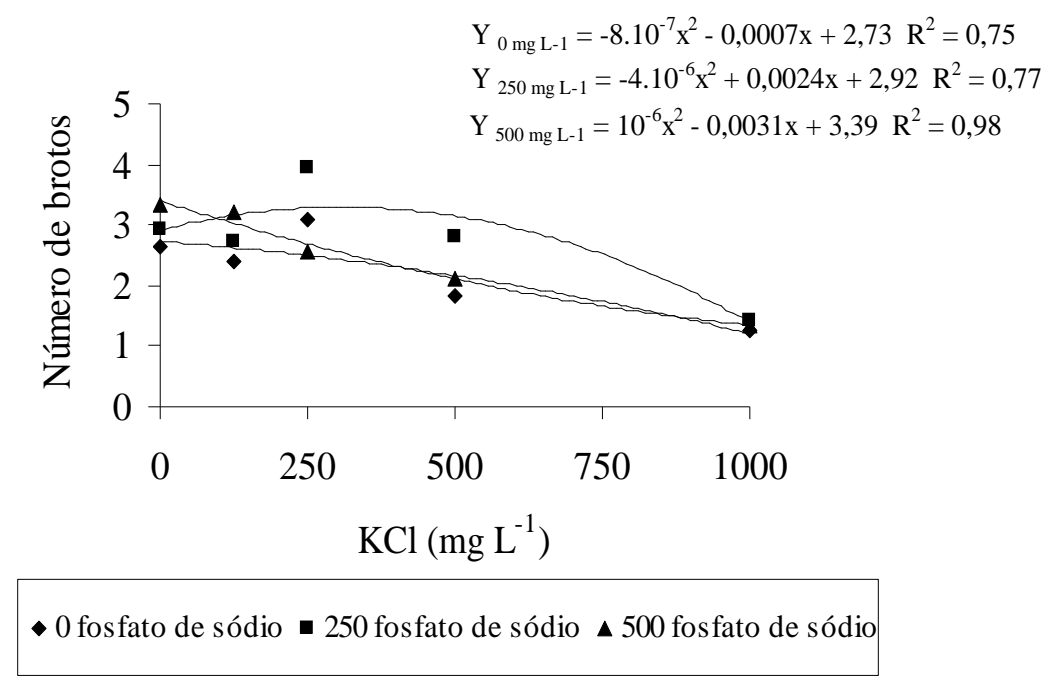

Figura 2 - Número de brotos de plantas de amoreira-preta cv. Tupy em diferentes concentrações de cloreto de potássio $(\mathrm{KCl})$ e fosfato de sódio $\left(\mathrm{NaH}_{2} \mathrm{PO}_{4} \cdot \mathrm{H}_{2} \mathrm{O}\right)$. UFLA, Lavras, MG.

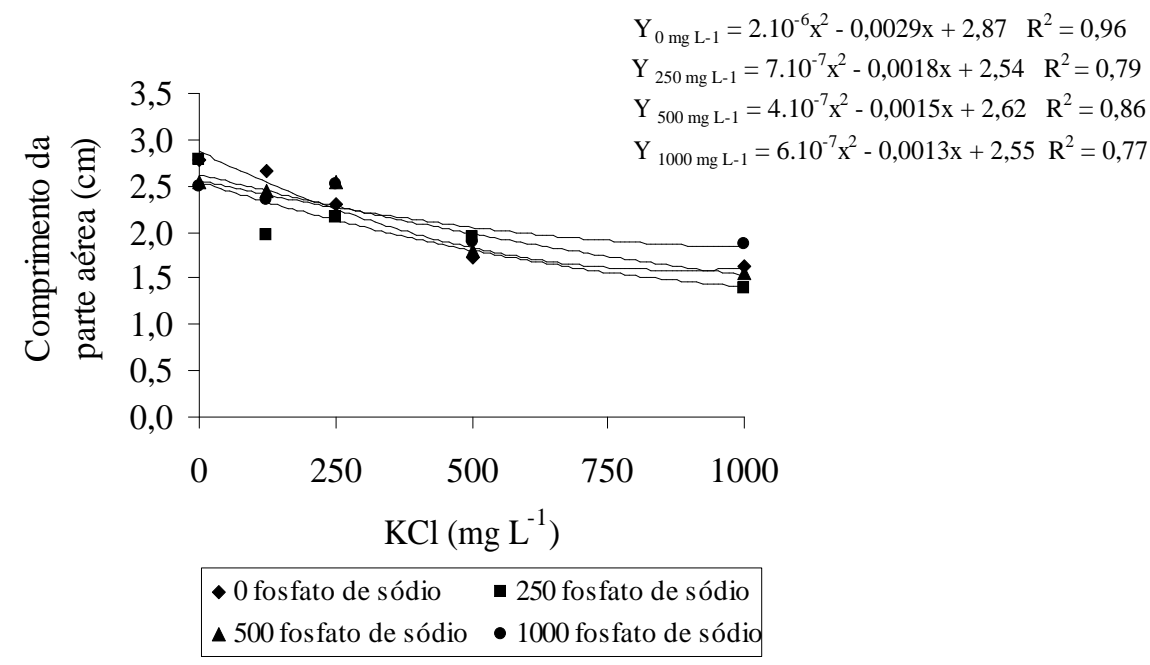

Figura 3 - Comprimento da parte aérea de plantas de amoreira-preta cv. Tupy em diferentes concentrações de cloreto de potássio $(\mathrm{KCl})$ e fosfato de sódio $\left(\mathrm{NaH}_{2} \mathrm{PO}_{4} \cdot \mathrm{H}_{2} \mathrm{O}\right)$. UFLA, Lavras, MG. 
Altas concentrações de fosfato de sódio diminuíram o crescimento do explante, conforme já citado por Pasqual (2001), possivelmente porque o sódio e alguns microelementos são precipitados da solução ou sua absorção é reduzida. A taxa de incorporação de íons fosfato depende do genótipo, que é usualmente constante e proporcional à taxa de crescimento da cultura.

Maior matéria fresca de calos $(1,05 \mathrm{~g})$ foi obtida na ausência dos dois sais no meio de cultura MS (Figura 4). Em estudos com orquídeas Phalaenopsis nebula, verificou-se regeneração de plantas através de cultura de calos, em meio de cultura MS, com a adição de $170 \mathrm{mg} \mathrm{L}^{-1}$ de fosfato de sódio (CHEN et al., 2000).

Resultados muito próximos foram observados para matéria fresca de plantas de amoreira-preta. Com o aumento das concentrações de cloreto de potássio, houve uma queda da matéria fresca da parte aérea. Com $125 \mathrm{mg} \mathrm{L}^{-1} \mathrm{de}$ $\mathrm{NaH}_{2} \mathrm{PO}_{4} \cdot \mathrm{H}_{2} \mathrm{O}$, as plantas tiveram respostas positivas para esta variável, verificando-se um crescimento da matéria fresca a partir de $500 \mathrm{mg} \mathrm{L}^{-1}$ de $\mathrm{KCl}$ (Figura 5).

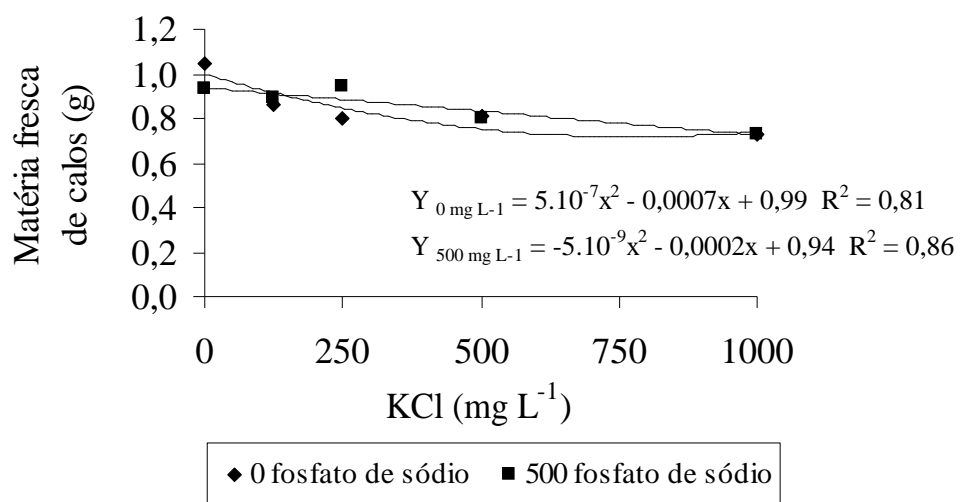

Figura 4 - Matéria fresca de calos de plantas de amoreira-preta cv. Tupy em diferentes concentrações de cloreto de potássio $(\mathrm{KCl})$ e fosfato de sódio $\left(\mathrm{NaH}_{2} \mathrm{PO}_{4} \cdot \mathrm{H}_{2} \mathrm{O}\right)$. UFLA, Lavras, MG.

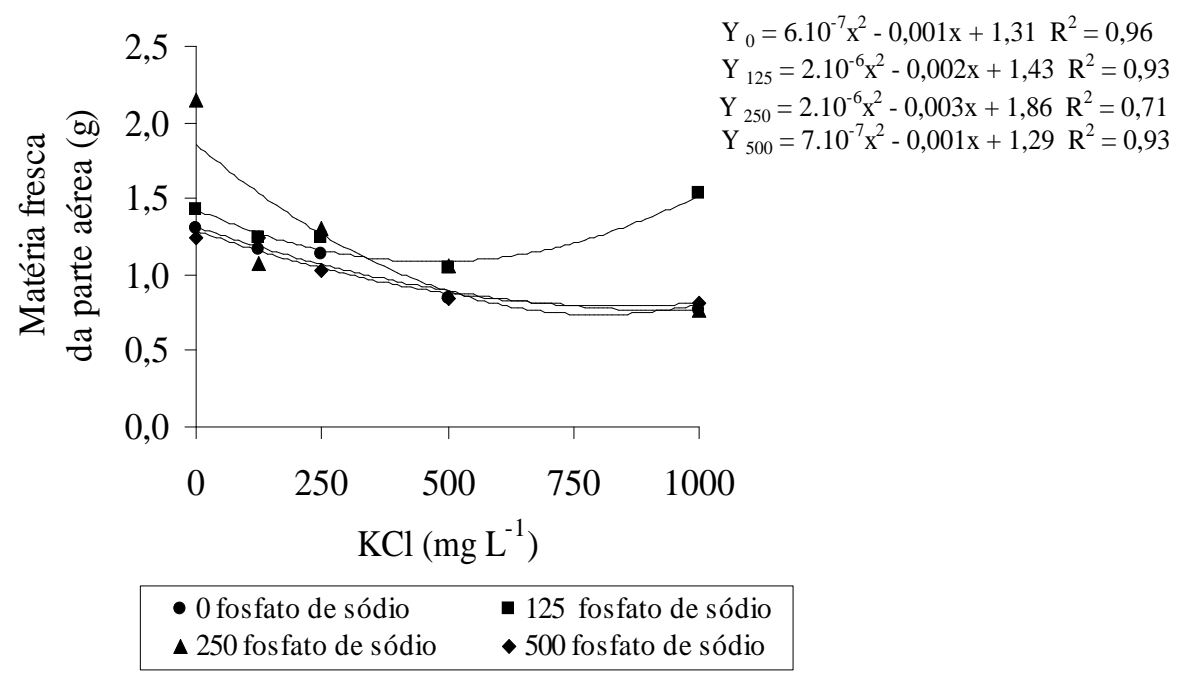

Figura 5 - Matéria fresca de plantas de amoreira-preta cv. Tupy em diferentes concentrações de cloreto de potássio $(\mathrm{KCl})$ e fosfato de sódio $\left(\mathrm{NaH}_{2} \mathrm{PO}_{4} \cdot \mathrm{H}_{2} \mathrm{O}\right)$. UFLA, Lavras. 


\section{CONCLUSÕES}

O uso de cloreto de potássio reduz o número de brotos e o comprimento da parte aérea das plantas de amoreira-preta cv. Tupy.

Melhores resultados foram obtidos na ausência de $\mathrm{KCl}$ e na presença de $\mathrm{NaH}_{2} \mathrm{PO}_{4} \cdot \mathrm{H}_{2} \mathrm{O}$, principalmente para comprimento e matéria fresca da parte aérea.

\section{REFERÊNCIAS BIBLIOGRÁFICAS}

ANTUNES, L. E. C.; RASEIRA, M. C. B. Aspectos técnicos da cultura da amora-preta. Pelotas: Embrapa Clima Temperado, 2004. (Documentos, 122).

CALDAS, L. S.; HARIDASAN, P.; FERREIRA, M. E. Meios nutritivos. In: TORRES, A. C.; CALDAS, L. S.; BUSO, J. A. (Eds.). Cultura de tecidos e transformação genética de plantas. Brasília, DF: Embrapa/CNPH, 1998. v. 1, p. 87-132.

CHEN, Y.; CHANG, C.; CHANG, W. A reliable protocol for plant regeneration from callus culture of Phalaenopsis. In Vitro Cellular and Developmental Biology-Plant, Arkansas, v. 36, n. 5, p. 420-423, Oct. 2000.

DONNELLY, D. J.; DAUBENY, H. Tissue culture of Rubus species. Acta Horticulturae, Wageningen, v. 183, p. 305314, 1986.

FERREIRA, D. F. Análises estatísticas por meio do Sisvar para Windows versão 4.0. In: REUNIÃO ANUAL DA REGIÃO BRASILEIRA DA SOCIEDADE INTERNACIONAL DE BIOMETRIA, 45., 2000, São Carlos. Anais... São Carlos: UFSCar, 2000. p. 225-258.
FINNE, A. Micropropagation of Rubus spp. Journal of Agricultural Science of Finland, [S.1.], v. 58, p. 193-196, 1986.

GAMBORG, O. L.; MILLER, R. A.; OJIMA, K. Nutrient requirements of suspension cultures of soybean root cells. Experimental Cell Research, New York, v. 50, p. 151-158, 1968.

JENNINGS, D. L.; McNICOL, R. J. Rubus breeding: recent progress and problems. Plant Breeding Abstracts, Farnham Royal, v. 61, p. 753-758, 1991.

JUNQUEIRA, K. P.; RODRIGUES, V. A.; SANTOS, F. C.; PASQUAL, M. Crescimento in vitro de crisântemo: efeito do nitrato de cálcio $\left(\mathrm{Ca}\left(\mathrm{NO}_{3}\right)_{2} \cdot 4 \mathrm{H}_{2} \mathrm{O}\right.$ e cloreto de potássio (KCl). In: CONGRESSO BRASILEIRO DE FLORICULTURA E PLANTAS ORNAMENTAIS, 14.; CONGRESSO BRASILEIRO DE CULTURA DE TECIDOS DE PLANTAS, 1., 2003, Lavras. Anais... Lavras: UFLA, 2003. p. 197.

LEONTIEV-ORLOV, O. Propagation of plant of Rubus generation by the method of cutting. Proceedings of Problems of Modern Horticulture, California, p. 37, 1989.

MURASHIGE, T.; SKOOG, F. A revised medium for rapid growth and bioassays with tobacco tissue cultures. Physiologia Plantarum, Copenhagen, v. 15, p. 473-497, 1962.

PASQUAL, M. Cultura de tecidos vegetais: tecnologia e aplicações: meios de cultura. Lavras: UFLA/FAEPE, 2001. 74 p.

WHITE, P. R. A handbook of plant tissue culture. Lancaster: J. Cotteil, 1963. 345 p. 